\title{
Pengaruh Kepemimpinan terhadap Kinerja Dosen dan Karyawan STIKES NU Tuban
}

\author{
Sugiyono \\ Sekolah Tinggi Ilmu Kesehatan Nahdlatul Ulama Tuban \\ hafizh.hak@gmail.com
}

\begin{abstract}
To achieve a high level of performance, of course depends on various factors that influence it. There are at least six external factors that determine the level of performance of an employee, namely: (a) environment, (b) management behavior, (c) job design, $(d)$ education level, $(e)$ training, $(f)$ motivation and $(g)$ administration payment. The purpose of this study was to analyze the effect of leadership on the performance of Stikes NU lecturers and staff in Tuban.

The research method is descriptive research, the population of all lecturers and staff of STIKES NU Tuban is 120 people, the sample is divided into 3 groups (group 1 (17 people), group 2 (27 people), and group 3 (76 people)). Techniques for collecting data through observation and interviews. Data analysis uses Pearson Product moment (PPM). Based on the results of the study indicate that leadership has a significant effect on the performance of lecturers and employees in a positive direction. In addition to supporting the second hypothesis which states that leadership has a significant effect on the performance of lecturers and employees. Leadership applied by STIKES NU Tuban has been felt in accordance with the expectations and desires of lecturers and employees in the long term and caused lecturers and employees to be loyal to STIKES NU Tuban.
\end{abstract}

Keywords: Leadership, Performance, Stikes NU lecturers

\section{Abstrak}

Untuk mencapai tingkat kinerja yang tinggi tentu sangat bergantung pada berbagai faktor yang mempengaruhinya. Setidaknya ada enam faktor eksternal yang menentukan tingkat kinerja seseorang pegawai yaitu: (a) lingkungan, (b) perilaku manajemen, (c) design jabatan, (d) jenjang pendidikan, (e) pelatihan, (f) motivasi dan (g) administrasi pengupahan. Tujuan penelitian ini untuk menganalisis Pengaruh kepemimpinan terhadap kinerja dosen dan karyawan Stikes NU Tuban.

Metode penelitian ini deskriptif research, populasi seluruh dosen dan karyawan STIKES NU Tuban sejumlah 120 orang, sampel dibagi menjadi 3 golongan ( golongan 1 (17 orang), golongan 2 (27 orang), dan golongan 3 (76 orang)). Teknik pengumpulan data melalui observasi dan wawancara. Analisa data menggunakan Pearson Product moment (PPM). Berdasarkan hasil penelitian menunjukkan bahwa kepemimpinan berpengaruh signifikan terhadap kinerja dosen dan karyawan dengan arah positif. Selain mendukung hipotesis kedua yang menyatakan bahwa kepemimpinan berpengaruh signifikan terhadap kinerja dosen dan karyawan, kepemimpinan yang diterapkan oleh STIKES NU Tuban telah dapat dirasakan sesuai dengan harapan dan keinginan dosen dan karyawannya dalam jangka panjang dan menyebabkan dosen dan karyawan menjadi loyal terhadap STIKES NU Tuban.

Kata Kunci: Kepemimpinan, Kinerja, Dosen STIKES NU tuban

Alamat korespondensi :

Jl. P. Diponegoro 17, Kingking

STIKES NU

Tuban, Jawa Timur 


\begin{tabular}{lrl}
\hline Permalink/DOI & $:$ & http://dx.doi.org/10.32503/jmk.v4i3.544 \\
Cara Mengutip & $:$ & Sugiono. (2019). Pengaruh Kepemimpinan terhadap Kinerja \\
& Dosen dan Karyawan STIKES NU Tuban. JMK (Jurnal \\
& Manajemen dan Kewirausahaan), 4 (3), 174-181 doi: \\
& http://dx.doi.org/10.32503/jmk.v4i3.544 \\
Sejarah Artikel $:$ & Artikel diterima 1 Juli 2019; direvisi 4 Agustus 2019; disetujui \\
& 15 Agustus 2019
\end{tabular}

\section{Pendahuluan}

Dalam upaya untuk meningkatkan sumber daya manusia (SDM) tidak ada upaya lain yang lebih tepat selain melalui peningkatan pendidikan, yaitu pengetahuan dan ketrampilan bangsa Indonesia yang lebih merata. Dengan peningkatan pendidikan di bidang pengetahuan dan keterampilan sebagian sumber daya manusia Indonesia, akan dapat menjadi landasan dalam melakukan berbagai peningkatan di bidang ekonomi, sehingga dapat meningkatkan kesejahteraan rakyat dan kemakmuran bangsa Indonesia semakin terjamin.

Keberhasilan dan kegagalan sebuah lembaga pendidikan dalam menjalankan program-program kerjanya disebabkan oleh beberapa faktor, diantaranya adalah faktor Sumber Daya Manusia (SDM) dalam sebuah organisasi. Sumber daya yang ada akan dapat berfungsi secara maksimal kalau diimbangi dengan kepemimpinan (leadership) yang tepat dari para pemimpinnya. Leadership dianggap tepat kalau sesuai dengan kondisi anggota dalam organisasi dengan pengaruh yang dimilikinya untuk mewujudkan kinerja yang maksimal.

Kinerja sendiri merupakan perwujudan kerja yang dilakukan oleh karyawan yang biasanya dipakai sebagai dasar penilaian terhadap karyawan atau organisasi. Kinerja yang baik merupakan suatu langkah untuk menuju tercapainya tujuan organisasi. Oleh karena itu, kinerja merupakan sarana penentu dalam mencapai tujuan organisasi. Sehingga perlu diupayakan untuk meningkatkan kinerja karyawan, tetapi hal ini tidak mudah sebab banyak faktor yang mempengaruhi tinggi rendahnya kinerja seseorang.

\section{Tinjauan Pustaka}

\section{A. Kepemimpinan.}

\section{a. Pengertian Kepemimpinan}

Kepemimpinan adalah kepribadian yang dimiliki oleh seorang direksi. Kepemimpinan adalah merupakan kemampuan memerintah dan mempengaruhi orang lain agar mau melaksanakan sesuatu pekerjaan sesuai dengan keinginannya. Dengan kata lain kepemimpinan adalah kemampuan memerintah dan mempengaruhi orang lain untuk melaksanakan sesuatu pekerjaan agar tujuan yang telah ditetapkan dapat tercapai.

Gary (2009) menyatakan bahwa "kepemimpinan adalah proses yang disengaja dari seseorang untuk membua struktur, memfasilitasi aktivitas dan hubungan di dalam kelompok atau organisasi".

Handoko (2008) menyatakan: “ Kepemimpinan merupakan kemampuan yang dipunyai seseorang untuk mempengaruhi orang - orang 
lain agar bekerja mencapai tujuan dan sasaran. Manajemen mencakup kepemimpinan, tetapi juga mencakup fungsi - fungsi lain seperti perencanaan, pengorganisasian, dan pengawasan".

\section{b. Gaya - Gaya Kepemimpinan}

Gaya kepemimpinan (leadership style) seorang pemimpin akan sangat berpengaruh terhadap kinerja karyawan dan pencapaian tujuan perusahaan. Pemilihan gaya kepemimpinan yang benar dan tepat dapat mengarahkan pencapaian tujuan perseorangan maupun organisasi dan perusahaan. Dengan gaya kepemimpinan yang tidak sesuai dapat mengakibatkan pencapaian tujuan perusahaan akan terabaikan dan pengarahan terhadap karyawan akan menjadi tidak jelas.

Kelengkapan persyaratan kepemimpinan yang dimiliki oleh setiap piminan adalah berbeda saty sama lain. Juga pemimpin dalam mempengaruhi orang lain ditentukan oleh faktor - faktor antara lain, yakni seperti keterampilan, bakat, kemampuan, sifat dan karakter yang dimiliki.

Handoko (2008, hal. 299) berpendapat "para peneliti telah mendefenisikan dua gaya kepemimpinan : gaya dengan orientasi tugas (task - oriented) dan gaya dengan orientasi karyawan (employee - oriented)".

Gaya dengan orientasi tugas (task - oriented) Manajer berorientasi tugas mengarahkan dan mengawasi bawahan secara tertutup untuk menjamin bahwa tugas dilaksanakan sesuai yang di inginkannya. Manajer dengan gaya kepemimpinan ini lebih memperjatikan pelaksanaan pekerjaan daripada pengembangan dan pertumbuhan karyawan.

Gaya dengan orientasi karyawan (employee - oriented). Gaya berorientasi karyawan mencoba untuk lebih memotivasi bawahan dibanding mengawasi mereka. Mereka mendorong para anggota kelompok untuk melaksanakan tugas - tugas dengan memberikan keputusan, menciptakan suasana persahabatan serta hubungan hubungan saling mempercayai dan menghormati degnan para anggota kelompok.

\section{B. Kinerja \\ a. Pengertian Kinerja}

Dalam melaksanakan kerjanya, pegawai menghasilkan sesuatu yang disebut dengan kinerja. Kinerja adalah hasil kerja seorang pegawai selama periode tertentu dibandingkan dengan berbagai kemungkinan misalnya standard, target/sasaran atau kinerja yang telah ditntukan terlebih dahulu dan disepakati bersama.

Mangkunegara

(2009)

menyatakan bahwa : "kinerja adalah hasil kerja secara kualitas dan kuantitas yang dicapai oleh seseorang pegawai dalam melaksanakan tugasnya sesuai dengan tanggung jawab yang diberikan kepadanya”.
b. Faktor - fakor Yang Mempengaruhi Kinerja
Banyak faktor yang mempengaruhi kinerja seorang pegawai. Faktor yang mempengaruhi pencapaian kinerja yang baik. Faktor - faktor yang mempengaruhi kinerja menurut perusahaan pada umumnya 
untuk memindahkan karyawan dari satu pekerjaan ke pekerjaan yang lain ianggap atau sejajar dipengaruhi oleh beberapa faktor, baik yang berhubungan dengan tenaga kerja itu sendiri.

\section{Metodologi Penelitian}

Penelitian deskriptif
(descriptive research), dan penelitian penjelasan (explanative research).

Berdasarkan pengelompokan tersebut, penelitian ini termasuk dalam penelitian penjelasan (explanative research) karena penelitian ini bermaksud untuk menjelaskan hubungan kausal (sebab akibat) antar variabel melalui pengujian hipotesis yang telah dirumuskan.

Populasi penelitian ini adalah dosen dan karywan STIKES NU Tuban yang berjumlah 120 orang, teknik sampling teknik sensus. Adapun perincian ukuran sampel pada masing-masing strata golongan kepangkatan dosen dan karyawan pada STIKES NU Tuban adalah sebagai berikut :

1. Golongan III (tiga) $=76$ orang dosen dan karyawan;

2. Golongan II (dua) = 27 orang dosen dan karyawan;

3. Golongan I (satu) = 17 orang dosen dan karyawan

Pengumpulan data melalui observasi, wawancara dan kuisioner. Uji statistik dengan anaslis jalur (Path Analysis) dan tingkat kemaknaan $\alpha=$ 0,05 atau $\mathrm{p} \leq 0,05$.

\section{Hasil}

\section{Diskripsi Penilaian Responden Terhadap Kepemimpinan}

Berdasarkan uraian kelima indikator tersebut diketahui bahwa dari total 120 responden persentase jawaban responden untuk nilai 5 berjumlah $23,48 \%$, untuk nilai 4 berjumlah $53,82 \%$, untuk nilai 3 berjumlah $16,02 \%$, dan untuk nilai 2 berjumlah $5,82 \%$, serta nilai 1 berjumlah $\quad 0,66 \%$. Responden dikategorikan memiliki persepsi yang sangat tinggi jika nilai jawaban terletak pada interval 4, 1sampai dengan 5, tinggi jika nilai jawaban terletak pada interval 3, 1 sampai dengan 4 , , netral jika nilai jawaban terletak pada interval 2, 1 sampai dengan 3 , rendah jika nilai jawaban terletak pada interval 1,1 sampai dengan 2, sangat rendah jika nilai jawaban terletak pada interval 0,1 sampai dengan 1. Penilaian responden untuk kelima indikator kepemimpinan memiliki nilai rata-rata skor 3,92 yaitu memiliki persepsi yang baik terhadap kepemimpinan yang diterapkan oleh institusi.

\section{Diskripsi Penilaian Responden Terhadap Kinerja dosen dan karyawan}

Seluruh responden persentase jawaban responden untuk nilai 5 berjumlah $14,35 \%$, untuk nilai 4 berjumlah $41,9 \%$, untuk nilai 3 berjumlah $35,2 \%$, dan untuk nilai 2 berjumlah $7,73 \%$, serta nilai 1 berjumlah $\quad 0,8 \%$. Responden dikategorikan memiliki persepsi yang sangat tinggi jika nilai jawaban terletak pada interval 4,1 sampai dengan 5, tinggi jika nilai jawaban terletak pada interval 3,1 sampai dengan 4, netral jika nilai jawaban terletak pada interval 2,1 sampai dengan 3 , rendah jika nilai jawaban terletak pada interval 1,1 sampai 
dengan 2, sangat rendah jika nilai jawaban terletak pada interval 0,1 sampai dengan 1. Penilaian responden untuk ketiga indikator kinerja dosen dan karyawan memiliki nilai rata-rata skor 3,6 yaitu memiliki persepsi yang baik terhadap kinerja dosen dan karyawan terhadap STIKES NU Tuban.

Tabel 1. Nilai Jawaban Responden

\begin{tabular}{|c|c|c|c|c|c|c|c|c|c|c|c|c|c|}
\hline \multirow{3}{*}{ No. } & \multirow{3}{*}{$\begin{array}{l}\text { Indi- } \\
\text { kator }\end{array}$} & \multicolumn{10}{|c|}{ Nilai Jawaban Responden } & \multirow{3}{*}{ Jumlah } & \multirow{3}{*}{$\begin{array}{l}\text { Mean } \\
\text { Skor }\end{array}$} \\
\hline & & \multicolumn{2}{|r|}{1} & \multicolumn{2}{|c|}{2} & \multicolumn{2}{|r|}{3} & \multicolumn{2}{|r|}{4} & \multicolumn{2}{|r|}{5} & & \\
\hline & & $\mathbf{f}$ & $\%$ & $\mathbf{f}$ & $\%$ & $\mathbf{f}$ & $\%$ & f & $\%$ & f & $\%$ & & \\
\hline 1. & $\mathrm{X} 1 . .1$ & & & 4 & 3.3 & 8 & 6.7 & 71 & 58.3 & 37 & 30.8 & 120 & 4,18 \\
\hline 2. & $\mathrm{X} 1 . .2$ & 1 & 0.8 & 3 & 2.5 & 15 & 12.5 & 73 & 60.8 & 28 & 23.3 & 120 & 4,00 \\
\hline 3. & $\mathrm{X} 1.3$ & 1 & 0.8 & 10 & 8.3 & 29 & 24.2 & 53 & 44.2 & 27 & 22.5 & 120 & 3,758 \\
\hline 4. & $\mathrm{X} 1.4$ & 2 & 1.7 & 16 & 13.3 & 35 & 29.2 & 46 & 38.3 & 21 & 17.5 & 120 & 3,55 \\
\hline 5. & X1.5 & - & & 2 & 1.7 & 9 & 7.5 & 81 & 67.5 & 28 & 23.3 & 120 & 4,108 \\
\hline $\begin{array}{l}\text { Rata- } \\
\text { rata X1 }\end{array}$ & & & 0,66 & & 5,82 & & 16,02 & & 53,82 & & 23,48 & & 3,92 \\
\hline
\end{tabular}

Sumber: Data Primer, (2019)

\section{Pembahasan}

Hasil analisis menunjukkan bahwa dosen dan karyawan memiliki persepsi yang tinggi terhadap kepemimpinan yang telah diterapkan oleh STIKES NU Tuban yang ditunjukkan oleh penilaian dosen dan karyawan atas kelima indikator kepemimpinan yang memiliki nilai rata-rata skor 3,92. Selain itu hasil analisis juga menunjukkan bahwa dosen dan karyawan merasakan motivasi kerja yang tinggi atas koordinasi yang dilakukan oleh STIKES NU Tuban ditunjukkan oleh penilaian konsumen atas ketiga indikator motivasi kerja pelanggan memiliki nilai skor rata-rata 4,022. Hasil ini mengandung makna bahwa kepemimpinan yang diberikan oleh STIKES NU Tuban telah mampu memenuhi harapan dosen dan karyawan nya, sehingga dosen dan karyawan merasa puas atas kepemimpinan yang diterapkan oleh STIKES NU Tuban.

Indikator yang paling kuat sebagai pengukur kepemimpinan adalah indikator komunikasi dengan nilai loading factor sebesar 0,942 yang merupakan nilai loading factor paling besar dibandingkan nilai loading factor indikator lainnya, sedangkan indikator yang paling lemah sebagai pengukur kepemimpinan adalah indikator gaya kepemimpinan dengan nilai loading factor 0,722 yang merupakan nilai loading factor paling kecil dibandingkan nilai loading factor indikator lainnya.

Kepemimpinan berpengaruh signifikan terhadap kinerja dosen dan karyawandengan arah hubungan positif atau kepemimpinan berpengaruh secara langsung pada kinerja dosen dan karyawan . Hal ini terlihat dari hasil koefisien jalur positif sebesar 0,188 dengan $\mathrm{CR}$ 
sebesar 1,999 dan diperoleh probabilitas yang signifikan (p) sebesar 0,46 yang lebih kecil dari taraf signifikan yang disyaratkan yaitu 0,05. Hasil ini mendukung hipotesis kedua pada penelitian ini yang berarti bahwa hipotesis kedua terbukti (diterima).

Dengan demikian, hasil analisis menunjukkan bahwa dosen dan karyawan memiliki persepsi yang tinggi atas variable-variabel kepemimpinan yang telah diterapkan oleh STIKES NU Tuban yang ditunjukkan oleh penilaian dosen dan karyawan atas kelima indikator kepemimpinan memiliki nilai ratarata skor 3,92. Selain itu, hasil analisis juga menunjukkan bahwa dosen dan karyawan telah merasakan kinerja yang tinggi atas koordinasi yang dilakukan oleh kepala STIKES NU Tuban yang ditunjukkan oleh penilaian dosen dan karyawan tersebut atas keempat indikator kinerja dosen dan karyawanyang memiliki nilai skor rata-rata 3,6 . Hal ini mengandung makna bahwa variable-variabel kepemimpinan yang diterapkan oleh STIKES NU Tuban telah mampu memenuhi harapan dan keinginan dosen dan karyawan nya, sehingga dosen dan karyawan dapat merasa loyal terhadap STIKES NU Tuban.

Diketahui juga bahwa indikator yang paling kuat sebagai pengukur kinerja dosen dan karyawan adalah indikator waktu yang dibutuhkandengan nilai loading factor sebesar 0,915 yang merupakan nilai loading factor paling besar dibandingkan nilai loading factor indikator lainnya, sedangkan indikator yang paling lemah sebagai pengukur kepemimpinan adalah indikator niat kualitas kerja dengan nilai loading factor 0,786 yang merupakan nilai loading factor paling kecil dibandingkan nilai loading factor indikator lainnya.

\section{Simpulan}

Kepemimpinan berpengaruh signifikan terhadap kinerja dosen dan karyawan dengan arah positif. Selain mendukung hipotesis kedua yang menyatakan bahwa kepemimpinan berpengaruh signifikan terhadap kinerja dosen dan karyawan, hasil ini juga membuktikan bahwa variabelvariabel kepemimpinan yang diterapkan oleh STIKES NU Tuban telah dapat dirasakan sesuai dengan harapan dan keinginan dosen dan karyawannya dalam jangka panjang dan menyebabkan dosen dan karyawan menjadi loyal terhadap STIKES NU Tuban.

\section{Daftar Pustaka}

Allred,B.B.Snow, Charles..Snow \& Raymond E. Miles,. 1996. "Characteristic of Managerial Career in The $21^{\text {st }}$ Century", Academy of Management Executive, 10 (4); 17-27.

Alwi, Syafaruddin. 2001. Manajemen Sumber Daya Manusia : $\quad$ Strategi Keunggulan Kompetitif, Edisi Pertama, Yogyakarta : penerbit BPFE UGM.

Anthon, Tonggo. 2003. Reformasi

Kebijakan Penerimaan CPNS, Artikel, "Bali Post-Online", Rabu Paing, 12 Nopember 2003, halaman 1 .

Amstrong Michael, 1998.

Manajemen Sumber Daya 
Manusia; PT. Elex Media Kompulindo, Jakarta

Becherer, Richaerd C. Fred W. Morgan and Lowrence, Mrichard, The Job

Charecteristic of Industrial Sales

Persons ; Relationship To Motivation and Statisfaction, Journal Of Marketing, Vol. 46, $1982: 125-135$

Desleer, Gary.1997. Human Resource Management, international edition ( 7 th ed.). New Jersey : Prentice-Hall, Inc.. alih bahasa Manajemen Sumber Daya Manusia oleh Benyamin Molan ( 1997 ), Jakarta : Penerbit PT.Prenhallindo.

Gibson, James L , et. al . 1992. Organisasi : Perilaku, Struktur dan Proses. Jilid I. Edisi V. Alih Bahasa : Djarkasin. Erlangga, Jakarta

Gutteridge, G.H, and Leibowitz, Z.B. and Shore,J.E. 1993. Organizational Career Development : benchmarks for building a world-class workforce, San Francisco:Jossey-Bass Publishers.

Harsey. Paul and Kenneth $\mathrm{H}$. Blanchard. 1986. Management Of Organization Behavior, Utilizing Human Resources, 4 th edition, Pretice Hall, inc, Terjemahan Agus Dharma , Erlangga, Jakarta

Thoha, Miftah.

(2006). Kepemimpinan Dalam

Manajemen. Suatu Pendekatan Perilaku, Jakarta: PT. RajaGrafindo Persada

Handoko, T. Hani. 1991. Manajemen, Edisi II. BPFE, Yogyakarta

James,J.J. dan Gary K.2000.
Supervisor Support and Career Anchor Impact on The Career Satisfaction of the Entry-Level Information Syistem Professional, Journal of Management Information System, 16 (3);219-240.

Koontz. Harrold, Crli O'Donnel and Heis Weihrich, 1989.

Manajemen, Erlangga, Jakarta Leibowitz,Z.B. and Schlosseberg, N.1981. Designing Career Development Program in Organization, in D.H.Montorss and C.S. Shinkmean (ads), Creer Development in the 1980's ; Theory and Practice, Charles C.Thomson, pp.277291. Springfield, IL.

Marlow,N.D.,E.K.Marlow, and ArnoldV.A.1995. "Career Development and Women Managers : Does one size fit all ? "Human Resource Planning, pp 38-49

Mathiew, John E. Scott I. Tannenbaum and Eduardo Sales, Influences of Individual and Situasional Charactiristics on Measures of Training Effectivenees, Akademy of Management Journal, Vol. 35, No.4, 1992 : $824-847$

Nadler, David A, and Edward E. Lawler III., and Lyman W. Porter, edc, Perpective on Behavior in Organizations, McGraw-Hill, New York 1977

Reksohadiprojo, S. dan T. Hani Handoko, 1990, Organisasi Perusahaan : Teori,Struktur dan Perilaku. Edisi II. BPFE, Yogyakarta

Stoner, James AF and Edward Freeman, 1989. Management Frouth Edition New Jersey : Englewood Cliffs 
Swasto Bambang, 1996.

Pengembangan Manajemen

Sumber Daya Manusia,

Pengaruhnya Terhadap

Kinerja dan Imbalan,

Fakultas Ilmu Administrasi

Universitas Brawijaya

Walizer, et. al. 1990, Metode dan

Analisis Penelitian,

diterjemahkan Sukadiman, Jilid

I, Erlangga, Jakarta

Walker, J.W.1988. Managing Human

Resource in Flat, Lean, and

Flexible Organization :Trends

for the 1990's' Human

Resource Planing, 11(2) : 125-

132. 